\title{
ORIG I N A RESEARCH \\ A comparative analysis of policies addressing rural oral health in eight English-speaking OECD countries
}

\author{
LA Crocombe, LR Goldberg, E Bell, B Seidel \\ University of Tasmania, Hobart, Tasmania, Australia
}

Submitted: 17 November 2015; Revised: 6 March 2016, Accepted: 23 March 2017; Published: 31 July 2017

Crocombe LA, Goldberg LR, Bell E, Seidel B

A comparative analysis of policies addressing rural oral health in eight English-speaking OECD countries Rural and Remote Health 17: 3809. (Online) 2017

Available: http://www.rrh.org.au

\section{A B S T R A C T}

Introduction: Oral health is fundamental to overall health. Poor oral health is largely preventable but unacceptable inequalities exist, particularly for people in rural areas. The issues are complex. Rural populations are characterised by lower rates of health insurance, higher rates of poverty, less water fluoridation, fewer dentists and oral health specialists, and greater distances to access care. These factors inter-relate with educational, attitudinal, and system-level issues. An important area of enquiry is whether and how national oral health policies address causes and solutions for poor rural oral health. The purpose of this study was to examine a series of government policies on oral health to (i) determine the extent to which such policies addressed rural oral health issues, and (ii) identify enabling assumptions in policy language about problems and solutions regarding rural communities.

Methods: Eight current oral health policies were identified from Australia, New Zealand, Canada, the USA, England, Scotland, Northern Ireland, and Wales. Validated content and critical discourse analyses were used to document and explore the concepts in these policy documents, with a particular focus on the frequency with which rural oral health was mentioned, and the enabling assumptions in policy language about rural communities.

Results: Seventy-three concepts relating to oral health were identified from the textual analysis of the eight policy documents. The rural concept addressing oral health issues occurred in only $2 \%$ of all policies and was notably absent from the oral health policies of countries with substantial rural populations. It occurred most frequently in the policy documents from Australia and Scotland, less so in the policy documents from Canada, Wales, and New Zealand, and not at all in the oral health policies from the US, England, and Northern Ireland. Thus, the oral health needs of rural communities were generally not the focus of, nor included in, the oral health policy documents in this study. When the language of concepts related to rural oral health was examined, the qualitative analysis identified four discourse themes related to both causality and solutions. These ranked discourse themes focused on service models, workforce issues, social determinants of health, and prevention. None of the policies addressed the structural economic 
determinants of unequal rural oral health, nor did they specifically assert the rights of children in rural communities to equitable oral health care.

Conclusions: This study documented the limited focus on rural oral health that existed in national oral health policies from eight different English-speaking countries. It supports the need for an increased focus on rural oral health issues in oral health policies, particularly as increased oral health is clearly associated with increased general health. It speaks to the critical importance of periodic analysis of the content of oral health policies to ensure that issues of inequality are addressed. Further, it reinforces the need for research findings about effective oral health care to be translated into practice in the development of practical and financially viable policies to make access to oral health care more equitable, particularly for people living in rural and remote areas.

Key words: oral health policy, rural inequality, rural inequity, rural oral health, rural policy.

\section{Introduction}

Oral health is fundamental to overall health and wellbeing ${ }^{1,2}$. Oral health diseases have a profound and adverse effect on people's lives, influencing eating, sleeping, work, and social function $^{3-6}$. These diseases are expensive to treat, with dental care accounting for $5 \%$ of the health budget and $16 \%$ of the private health expenditure in the 34 member countries of the Organisation for Economic Cooperation and Development $(\mathrm{OECD})^{1,7,8}$. This cost increases when oral health-related issues such as unplanned hospitalisations for aspiration pneumonia, heart disease, and diabetes are taken into account ${ }^{9}$. Thus, expenses associated with rectifying the effects of poor oral health have become a major component of the global public health burden ${ }^{10}$.

The recognised rural/urban oral health gap is a longestablished part of the public health challenge ${ }^{11}$. In Australia, Canada, and the United States, children and adults living in rural areas have poorer access to dental care, higher rates of dental caries, and, for adults, greater prevalence of edentulism (loss of all teeth) than people living in urban $\operatorname{areas}^{12-18}$. Indigenous children and adults are at particular risk $^{19,20}$. Although the oral health of rural Australians improved over the 17 years between 1987-1988 and 2004$2006^{21}$, there were similar improvements in oral health in capital city areas. Thus, the gap in oral health outcomes remained as great in 2004-2006 as it was in 1987-1988 ${ }^{22}$.
The disparities in oral health between urban and rural areas are complex. Rural populations are characterised by lower rates of health insurance, higher rates of poverty, less water fluoridation, fewer dentists and oral health specialists per population, and greater distances to travel to access care than urban populations ${ }^{14,15}$. These factors interrelate with educational, attitudinal, and system-level issues ${ }^{15,23}$. Regardless of economic differences, in many countries access to oral health services in rural areas exists as a complicated health challenge in which biopsychosocial interactions shape individual and community differences ${ }^{24}$.

The state of oral and general health in rural and remote communities may have worsened since the global financial crisis and the decline of public health and education infrastructure in many countries ${ }^{25}$. Addressing poor rural oral health requires engaging with the socioeconomic and biological determinants of health, and recognising the important relationship between poor oral health and chronic disease risk factors, such as diabetes, heart disease, and obesity $^{26,27}$. Facilitating equitable oral health services in rural areas will therefore require critical engagement with the way that issues of equity and equality are understood in policy and government-supported practices. The global oral health policy of $\mathrm{WHO}^{28}$ has created a framework for explicit national oral health policy recognising the critical link between oral health and general health, as well as the unequal oral health outcomes of disadvantaged communities, such as rural and Aboriginal communities ${ }^{26}$. To support the importance of implementing this framework, a comparative 
analysis of the adequacy of national policy for rural oral health is a pressing research priority.

The literature over the past decade in particular has suggested that policy-makers use a wide range of information to formulate policy ${ }^{29-32}$. Evidence about 'what works' is often poorly translated into policy, and political exigencies and policy-makers' values can drive decision-making ${ }^{29-34}$. Policies developed on faulty assumptions will be ineffective ${ }^{35-39}$. The health policy literature from Nutley and colleagues ${ }^{37-40}$ has confirmed the value of using sophisticated language-based analysis to identify enabling assumptions in policy language. The purpose of the current study was to examine a series of government policies on oral health, comparing policies in Australia to those in other English-speaking OECD countries, to (i) determine the extent to which such policies addressed rural oral health issues, and (ii) identify the key enabling assumptions about rural communities in policy language what has been defined as a problem (or cause) and what has been developed as a solution.

\section{Methods}

\section{Policy documents}

Eight oral health policy guidelines and planning statements, published since 2000 and written in English, were obtained from searches of government websites, media releases, and reports for OECD countries. A complementary literature search was conducted of 'oral health' OR 'dental' OR 'periodontal' AND 'policy' in Scopus for the health sciences from 2000 to 2014. The resulting identified policy documents from eight countries, published between 2004 and 2012, were as follows: Healthy mouths, healthy lives: Australia's national oral health plan 2004-2013 ${ }^{41}$; Good oral health for all, for life: The strategic vision for oral health in New Zealand $^{42}$; Oral health program, strategic plan for the USA, 2011$2014^{43}$; A Canadian oral health strategy - 2005-2010 ${ }^{44}$; Choosing better oral health: An oral health plan for England ${ }^{45}$; An action plan for improving oral health and modernising NHS dental services in Scotland $d^{46}$; Oral health strategy for Northern Ireland $d^{47}$; and Together for health: A national oral health plan for Wales (2013-18), a draft document that was later adopted ${ }^{48}$. The documents were scrutinised for relevance by an international oral health colleague, not involved in the study, who was familiar with comparative oral health policy developments.

\section{Data analysis}

The analysis was conducted in two stages. First, the documents were uploaded into Leximancer, a Bayesianbased, validated content analysis program ${ }^{49}$. In an initial analysis, the software automatically generated a corpus of policy-related terms. This corpus was reviewed by the researchers to ensure all selected terms were relevant to policy problems and solutions in rural oral health and to add any needed terms. Machine-selected terms included 'rural, Aboriginal, children, government, dental, practitioners, interventions'; added researcher-selected terms included 'culturally and linguistically diverse groups, disability, elderly' and 'special needs'. The number of concepts programmed for selection in subsequent steps in the analysis was intentionally large to ensure that the conceptual architecture of the policy documents was thoroughly scoped and no important term was missed. The final corpus of terms enabled a quantitative scoping of key concepts related to rural oral health in the content of the eight policy documents.

The second stage of the investigation focused on a qualitative discourse analysis of how policy problems and solutions about rural oral health were constructed in the eight documents. Critical discourse analysis is an application that allows researchers to examine how language works in subtle ways to reproduce or naturalise certain assumptions and make them seem unquestioned ${ }^{50}$. For this study, a discourse was defined as a distinct set of language (or block of text) that represented assumptions about causality versus language about policy solutions $^{51}$. When discourses included both content about causality and solutions, the blocks of text were further analysed to determine an individual focus. To conduct this critical discourse analysis, a rural health researcher (the third author) with a policy and critical discourse background, worked iteratively to (a) group each reference to rural oral 
health in terms of whether it was about causes or solutions, (b) describe the assumptions used in the policy language about causes and solutions, based on the evidence in the language sets, (c) classify assumptions about causes and solutions in the language sets in terms of key discourses, (d) rank order the key discourses to identify the hierarchy of discourses, from dominant to least dominant, then (e) link and refine the descriptions to develop findings about the way the assumptions were represented across the identified hierarchy of discourses.

These iterative findings were examined by a second investigator (the first author), a senior oral health practitioner and epidemiologist, to confirm that there were no important or systematic omissions, and that the findings were reasonable in light of the evidence of the policy documents.

\section{Ethics approval}

The Tasmanian Social Science Ethics Committee advised that ethics approval was unnecessary for this study because only existing published oral health policy documents were being accessed.

\section{Results}

\section{Key oral health policy concepts, including rural oral health}

Seventy-three concepts relating to oral health were identified from the textual analysis of the eight policy documents. Excluding concepts such as 'dental', 'health', and 'service', which were common across the policy documents, the language of the oral health policies was dominated (85\%) by concepts related to the dental workforce (40\%), scope of practice (35\%), and practitioner development (10\%). Examples of dental workforce concepts included 'prosthetists', 'assistants', and 'hygienists'; scope of practice concepts included 'treatment', 'orthodontic', and 'standards'; and practitioner development concepts included 'recruitment', funding', and 'training'. The remaining 15\% of identified concepts included the concepts of 'nutrition', 'residential', 'department', 'cultural', 'deprivation', and 'rural'.

The 'rural' concept occurred with only a $2 \%$ frequency in oral health policy language. When all 73 concepts were mapped to provide a visual display of the non-statistical linkages among concepts (Fig1), the 'rural' concept (sphere 1) typically was connected to service delivery concepts including 'care', 'quality', 'access', and 'barriers' (sphere 1), and situated close to workforce concepts (sphere 2). The concept of 'determinants' (sphere 3) occurred less frequently (1\%). This concept was not linked to the 'rural' concept but was linked to the concept of 'health' (sphere 4), which was common to all policy documents, either directly or indirectly. When concepts were paired to examine their likelihood of cooccurrence, the 'rural' concept occurred most frequently with the concepts of 'students' (43\%, sphere 1), 'recruitment' (36\%, sphere 1), 'Aboriginal' (30\%, sphere 5) and 'Torres Strait Islander' (29\%, sphere 5).

There were differences in the frequency of occurrence of the 'rural' concept when the oral health policy documents from the eight countries were examined individually. The 'rural' concept occurred most frequently in the policy documents from Australia and Scotland, where it had a $7 \%$ and $4 \%$, respectively, likelihood of occurring. The 'rural' concept was notably absent from the oral health policies of countries with substantial rural populations, occurring $1 \%$ of the time in the policy documents from Canada, Wales and New Zealand, and not at all in the oral health policies from the USA, England, and Northern Ireland.

\section{Dominant discourses in policy language about rural oral health}

The qualitative analysis of the language in the 'rural' oral health concept identified four discourses across policy language about causes and solutions. These discourses were based on assumptions about 'service models', 'workforce', 'social determinants of health', and 'prevention'. 


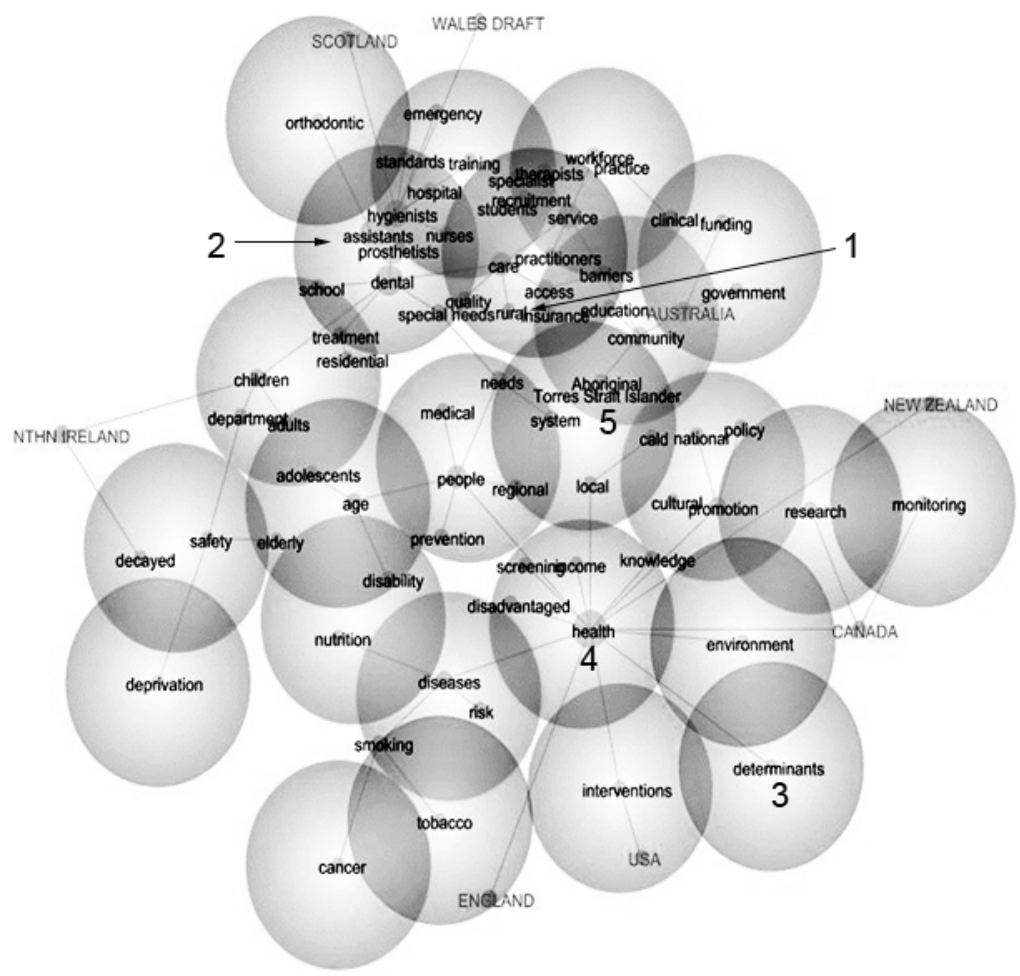

Figure 1: Map showing concepts identified from the content analysis of oral health policy documents from eight countries. The 'rural' concept is found in sphere 1 and is connected to service delivery concepts (sphere 1) and workforce concepts (sphere 2). The concept of 'determinants' is found in sphere 3; 'health' in sphere 4 and 'Aboriginal/Torres Strait islander' in sphere 5.

Causal policy language: Causal policy language in discourses that focused on 'service models' was identified primarily in the policy documents from Australia, New Zealand, Canada, and Scotland. The assumptions in this policy language varied, ranging from an access-economy assumption to do with 'who pays?' (Australia) to assumptions about the importance of declining infrastructure (New Zealand), cultural barriers presented by service delivery (Canada), and service design and complexity itself as a barrier to service delivery (Scotland).

A discourse on 'workforce' formed a less dominant but important body of causal policy in the documents from Australia and Scotland. In this workforce discourse, inequalities in rural oral health were assumed to be caused in part by unequal access to an adequate oral health workforce, and also to a specialised workforce. There was an assumption that rural and Aboriginal communities had equal rights to a culturally appropriate workforce; however, it was assumed that such rights could not always be exercised because of the many complex social factors that sift and sort health professionals into different geographical destinations.

A discourse on 'social determinants' was less evident across all policy documents but was particularly prominent in Australian oral health policy. This discourse focused on the assumptions of efficiency and economy in dealing with the complex, multifaceted, and challenging relationship between low socioeconomic status and unequal rural oral health. Assumptions about equity and social justice were scarce, 
although there were implied assumptions about the behavioural culpability of people who were socioeconomically disadvantaged.

Causal discourses related to prevention were not evident in language about rural oral health policy.

Solution-related policy language: Two dominant policy discourses were identified about solutions to inequality in rural oral health: (i) a discourse about service models (prominent in the policies from Australia, New Zealand, Canada, and Wales), followed by (ii) a discourse about workforce (prominent in the policies from Australia, Canada, and Scotland). These solution-related policy discourses paralleled those identified in the causal-related discourses. The discourse about service models focused on access to dental care. The discourse about workforce solutions focused on assumptions about the value of an expanded scope of practice, financial incentives, and improved workplace arrangements. Notably, the Australian policy emphasised 'rural origins' and 'rural exposure' as important assumptions about workforce development.

The least dominant cause- and solution-related policy discourse regarding the inequality in rural oral health was about prevention. This discourse was evident in the oral health policy documents from Australia and Canada, with the Canadian policy emphasising workforce preparation for prevention as a possible solution. The discourse on prevention shared the assumption that modifiable oral health behaviours were critical to improving unequal oral health outcomes. The importance of early childhood prevention was emphasised, but the right of all children to equal oral healthcare was not asserted. The Australian policy emphasised a community development approach to address inequality in rural oral health and positioned fluoridation as a key prevention solution for rural communities.

\section{Discussion}

The combination of validated content and critical discourse analyses in this study offered a valuable way in which to examine a series of OECD government policies about oral health and the inequalities that exist in Australia and internationally for people in rural communities. This combined method of analysis allowed an exploration of the concepts in policy documents and the enabling assumptions in policy language about rural communities - what has been defined as a problem, and what has been developed as a solution.

Of the 73 concepts identified in oral health policies from the eight OECD countries, the 'rural' concept occurred with only a $2 \%$ frequency. Thus, the oral health needs of rural communities were generally not the focus of, nor included in, the oral health policy documents in this study. When the language of concepts related to rural oral health was examined in more detail, four discourse themes of policy language related to both causality and solutions were identified. These ranked discourse themes focused on assumptions related to service models, workforce issues, social determinants of health, and prevention.

A factor common to the four identified thematic discourses was that they did not appear to be well informed by sound evidence and theory ${ }^{26-31}$. Narratives about the importance of service models were produced without recognition of the rights of people in rural communities to equitable oral health care, particularly for children and older adults. As it is unlikely that oral health services in rural areas will ever be equal to those in urban areas, the important issue here is equity rather than equality, and policies need to recognise and emphasise the nuanced difference between these two concepts. The recent change in the USA under the Obama presidency to make health care accessible and available for all reinforces the right of people in rural areas to equitable oral health in that country ${ }^{52}$. It is hoped that promoting equitable oral health in rural areas will continue under the Trump presidency.

Workforce issues in the examined policies often were assumed not to present distinct challenges in rural contexts. When policy documents referred to rural communities, they did not address the known socioeconomic drivers of unequal 
rural oral health ${ }^{24}$. Assumptions in policy language suggested that behavioural features of rural communities, rather than economic structural forces, lay at the heart of oral health inequality. There was a minimal focus on the prevention of inequalities in oral health in rural areas.

Overall, the analysis of the eight international policy documents suggested that the details of inequalities in rural oral health were situated within the larger conceptual architecture of oral health policy on service delivery, workforce development, socioeconomic determinants of health, and prevention. On one level, this conceptual approach may make sense. However, this larger conceptual approach also raised questions about how well the distinctiveness of service delivery and workforce issues in rural oral health were understood, and thus conveyed, in the policy documents. The approach also raised questions about whether and how well policies on oral health connected unequal rural health to socioeconomic causality and a focus on prevention.

The International Association for Dental Research ${ }^{53}$ has asserted that inequities in rural oral health, like inequities in general health, arise not simply from economic disparities but also from the policies that are purported to address such inequities. In the current study, the findings from the analysis of oral health policies in eight English-speaking OECD countries supported this assertion. For example, the Australian oral health policy emphasised that the largely private structure of dental services was a major part of the policy challenge for rural populations with unequal oral health. This finding resulted from a discourse about access and economy that centred on the cost of private oral health services. The discourse was conducted in a context in which private health insurance rebates from government were assisting mostly higher income earners, and people with lower incomes needing oral health services had long waiting lists $^{41}$. The New Zealand oral health policy placed greater emphasis on the challenge of economic disadvantage, focusing on declining rural and Indigenous oral health as one of declining public infrastructure and capacity ${ }^{42}$. In the Canadian oral health policy, unequal rural oral health was more strongly narrated as being about 'social access' or the cultural match between service models and clients, especially Aboriginal people and people from low socioeconomic backgrounds ${ }^{44}$.

More and more links are being found between poor oral health and poor general health and this is a particular concern for children and adults in rural areas. Earlier studies documented that periodontal pathogens can cross the placental barrier ${ }^{54,55}$, may be associated with pre-term/lowweight births ${ }^{56,57}$, but can be reduced through periodontal treatment ${ }^{58}$. More recent studies have shown that diabetes and periodontal disease are biologically linked ${ }^{59,60}$. Further, periodontitis adversely affects glycaemic control, a critical factor in diabetes prevention ${ }^{60}$, and periodontal treatment is an important factor in improving glycaemic imbalance ${ }^{\mathbf{1 0 , 6 1}}$. Periodontal disease also is thought to increase the risk for cardiovascular disease. For example, severe periodontitis has been associated with adverse changes in blood pressure and serum cholesterol levels ${ }^{62}$. In addition, it is possible that the accumulation of periodontal pathogens may increase the risk for respiratory tract infections, including aspiration pneumonia and chronic obstructive pulmonary disease ${ }^{63}$. Although the potential mechanisms are obscure, the most direct one involves the aspiration of pathogenic oral bacteria into the lungs. Well-controlled studies have documented the effectiveness of systematic oral care in preventing or reducing aspiration pneumonia and pneumonia-related transfers to hospital for adults with dementia ${ }^{64,65}$. Hence, if oral health policies were developed with a more specific focus on rural issues, the implementation of such policies would also facilitate improved general health outcomes for rural populations.

Those who provide oral health care in rural areas need to appreciate the theoretical and conceptual steps involved in policy development in order to communicate effectively in the effort to facilitate the connection between equitable service delivery and policy for people in rural communities. Similarly, policy developers need to recognise the role of practitioners. Practitioners may gravitate more to highlighting the actual social events needed to influence 
policy at any given time, thus focusing on the need to set policy agendas from a socio-cognitive perspective to recognise the implicit disadvantages, including access to oral health services, related to rural communities ${ }^{66}$. This need of practitioners to argue for immediate experience-relevant policies may prevent them from seeing the benefits of a structured agenda-setting approach based on the processes of (a) recognising the seriousness of a problem, (b) highlighting the feasibility, cost-effectiveness, and public resonance of the problem, (c) developing effective working relationships with elected officials who can advocate for the issue, and (d) creating or seizing windows of opportunity ${ }^{67}$. Clearly, there are advantages in melding both approaches with input from all stakeholders to develop public policies to broaden awareness of the need for oral health services and the availability of these services in rural areas. Subsequent investigations of the effectiveness of innovative models to implement value-based policies need to be outcome-based, documenting the use of services over time and the effect on health outcomes to ensure that policies guiding oral health services deliver what the evidence says is best for the care of people in rural communities.

After the analysis for this article was completed, the Australian National Oral Health Plan 2015-2024 was endorsed by the Australian Commonwealth and state governments $^{68}$. Its discourse was similar to the previous plan. Further research is needed on why the oral health of people living in rural areas is poorer than the oral health of people in metropolitan areas, why oral health policy does not reflect the research evidence, and methods of ensuring that it does.

\section{Limitations}

The search of published reports in English from OECD countries for this study was thorough. However, one potential limitation is that there may be other policies in nonOECD countries that address rural oral health that were not addressed. A second potential limitation is the use of Leximancer. Although Leximancer is a well-accepted research tool, it measures the frequency of policy recommendations, rather than the importance given to those policy recommendations.

\section{Conclusions}

This study documented the limited focus on rural oral health issues that existed in a series of national oral health policies from eight different English-speaking countries. It identified language relating to causality and solutions in references to rural oral health, forming four main discourses about service models, workforce, socioeconomic factors, and prevention. It demonstrated that a service model discourse dominated the other discourses across policies about both causality and solutions. A workforce discourse formed a lesser but important dominant discourse. A discourse of policy about ostensible socioeconomic causality was present but third in order of dominance. A discourse about solution-oriented prevention was the least present discourse in references to rural oral health concerns across all documents. These findings support the need for an increased and specific focus on rural oral health issues in oral health policy documents, particularly as increased oral health is clearly associated with increased general health. The study speaks to the critical importance of periodic analysis of the content of oral health policies to ensure that issues of inequality are addressed. Such periodic analysis also is important to ensure that research findings about effective oral health care are translated into practice in the development of practical and financially viable policies to make access to oral health care more equitable, particularly for people living in rural and remote areas.

\section{Acknowledgements}

The research reported in this paper was a project of the Australian Primary Health Care Research Institute, which was supported under the Australian Government's Primary Health Care Research, Evaluation and Development Strategy. The information and opinions contained in it do not necessarily reflect the views or policy of the Australian Primary Health Care Research Institute or the Department of Health and Ageing. 


\section{References}

1. World Health Organization. Global policy for improvement of oral health. (Internet) Available: http://www.who.int/oral_health/ publications/IDJ_June_08.pdf (Accessed 6 February 2016).

2. United States Department of Health and Human Services. Oral Health in America: a report of the surgeon general - executive summary. Rockville, MD: US Department of Health and Human Services, National Institute of Dental and Craniofacial Research, National Institutes of Health, 2000 .

3. Gerritsen AE, Allen PF, Witter DJ, Bronkhorst EM, Creugers $\mathrm{NH}$. Tooth loss and oral health-related quality of life: A systematic review and meta-analysis. Health and Quality of Life Outcomes 2010; 8: 126. https://doi.org/10.1186/1477-7525-8-126

4. Gift HC, Redford M. Oral health and quality of life. Clinics in Geriatric Medicine 1992; 8(3): 673-683.

5. Reisine ST. Dental disease and work loss. Journal of Dental Research 1984; 63(9): 1158-1161. https://doi.org/10.1177/ 00220345840630091301

6. Spencer AJ, Lewis JM. The delivery of dental services: Information, issues and directions. Community Health Studies 1988; 12(1): 16-30. https://doi.org/10.1111/j.1753-6405.1988. tb00569.x

7. Patel R. The state of oral health in Europe. Report commissioned by The Platform for Better Oral Health in Europe. (Internet) 2012. Available: http://www.mah.se/PageFiles/49503/Report - the State of Oral Health in Europe.pdf (Accessed 6 February 2016).

8. Petersen PE, Bourgeois D, Ogawa H, Estupinan-Day S, Ndiaye C. The global burden of oral diseases and risks to oral health. Bulletin of the World Health Organization 2005; 83(9): 661-669.

9. Kansagara D, Englander H, Salanitro A, et al. Risk prediction models for hospital readmission. Journal of the American Medical Association 2011; 306(15): 1688-1698. https://doi.org/10.1001/ jama.2011.1515
10. Griffin SO, Jones JA, Brunson D, Griffin PM, Bailey WD. Burden of oral disease among older adults and implications for public health priorities. American Journal of Public Health 2012; 102(3): 411-418. https://doi.org/10.2105/AJPH.2011.300362

11. Martin AB, Vyavaharkar M, Veschusio C, Kirby H. Ruralurban differences in dental service utilization among an early childhood population enrolled in South Carolina Medicaid. Maternal and Child Health Journal 2012; 16: 203-211. https://doi.org/ 10.1007/s10995-010-0725-1

12. Vargas CM, Dye BA, Hayes KL. Oral health status of rural adults in the United States. The Journal of the American Dental Association 2002; 133(12): 1672-1681. https://doi.org/10.14219/ jada.archive.2002.0120

13. Vargas CM, Ronzio CR, Hayes KL. Oral health status of children and adolescents by rural residence, United States. Journal of Rural Health 2003; 19(3): 260-268. https://doi.org/10.1111/ j.1748-0361.2003.tb00572.x

14. Skillman SM, Doescher MP, Mouradian WE, Brunson DK. The challenge to delivering oral health services in rural America. Journal of Public Health Dentistry 2010; 1(s): 49-57.

15. Fos $\mathrm{P}$, Hutchison L. The state of rural oral health. (Internet) 2010. Available: Available: http://www.srph.tamhsc.edu/ centers/rhp2010/10Volume1oralhealth.pdf (Accessed 6 February 2016).

16. Australian Institute of Health and Welfare, Dental Statistics and Research Unit. Geographic variation in oral health and use of dental services in the Australian population 2004 06. Adelaide, SA: AIHW, 2009.

17. Roberts-Thomson KF, Do L. Oral health status. In: GD Slade, AJ Spencer, KF Roberts-Thomson (Eds). Australia's dental generations: the national survey of adult oral health 2004-06. Canberra, ACT: Australian Institute of Health and Welfare, 2007; 81-142.

18. Harford J, Spencer AJ. Oral health perceptions. In: GD Slade, AJ Spencer, KF Roberts-Thomson (Eds). Australia's dental generations: The National Survey of Adult Oral Health 2004-06. Canberra, ACT: Australian Institute of Health and Welfare, 2007; 173-195. 
19. Mouradian W, Huebner C, DePaola D. Addressing health disparities through dental-medical collaborations, Part III: Leadership for the public good. Journal of Dental Education 2004; 68: 505-512.

20. Christian B, Blinkhorn A. A review of dental caries in Australian Aboriginal children: the health inequalities perspective. Rural and Remote Health (Internet) 2012; 2032. Available: www.rrh.org.au (Accessed 6 February 2016).

21. Slade GD, Sanders AE. Trends in oral health 1987-2006. In: GD Slade, AJ Spencer, KF Roberts-Thomson (Eds). Australia's dental generations: the national survey of adult oral health 2004-06. Canberra, ACT: Australian Institute for Health and Welfare, 2007; 196-235.

22. Crocombe LA, Stewart JF, Barnard PD, Slade GD, RobertsThomson K, Spencer AJ. Relative oral health outcome trends between people inside and outside capital city areas of Australia. Australian Dental Journal 2010; 55(3): 280-284. https://doi.org/ $10.1111 /$ j.1834-7819.2010.01235.x

23. Emami E, Feine JS. Focusing on oral health for the Canadian rural population. Canadian Journal of Rural Medicine 2008; 13(1): 36-38.

24. Hosseinpoor AR, Itani L, Petersen PE. Socio-economic inequality in oral healthcare coverage: results from the World Health Survey. Journal of Dental Research 2012; 91(3): 275-281. https://doi.org/10.1177/0022034511432341

25. SangNam A, Burdine JN, Smith ML, Ory MG, Phillips CD. Residential rurality and oral health disparities: influences of contextual and individual factors. Journal of Primary Prevention 2011; 32(1): 29-41. https://doi.org/10.1007/s10935-011-0233-0

26. Poul E. World Health Organization global policy for improvement of oral health -World Health Assembly 2007. International Dental Journal 2008; 58(3): 115-121. https://doi.org/ 10.1111/j.1875-595X.2008.tb00185.x
27. Marmot M, Bell R. Social determinants and dental health. Advances in Dental Research 2011, 23(2): 201-206. https://doi.org/ $10.1177 / 0022034511402079$

28. Petersen PE. Global policy for improvement of oral health in the 21 st century - implications for oral health research. Dental and Oral Epidemiology 2009; 37: 1-8. https://doi.org/10.1111/j.16000528.2008.00448.x

29. Dobbins M, Jack S, Thomas H, Kothari A. Public health decision-makers' informational needs and preferences for receiving research evidence. Worldviews on Evidence-Based Nursing 2007; 4(3): 156-163. https://doi.org/10.1111/j.1741-6787.2007.00089.x

30. Mays N, Pope C, Popay J. Systematically reviewing qualitative and quantitative evidence to inform management and policy-making in the health field. Journal of Health Services Research and Policy 2005; 10(Suppl 1): 6-20. https://doi.org/10.1258/ 1355819054308576

31. Sorian R, Baugh T. The power of information: closing the gap between research and policy. Health Affairs: The Policy Journal of the Health Sphere 2002; 21(2): 264-273. https://doi.org/10.1377/ hlthaff.21.2.264

32. Dobbins $M$, Rosenbaum $P$, Plews $N$, Law $M$, Fysh A. Information transfer: what do decision-makers want and need from researchers? Implementation Science 2007; 2(1): 20. https: / / doi.org/ $10.1186 / 1748-5908-2-20$

33. Bell E. Research for health policy. Oxford, UK: Oxford University Press, 2010.

34. Birnbaum R. Policy scholars are from Venus; policy makers are from Mars. The Review of Higher Education 2000; 23(2): 119-132. https://doi.org/10.1353/rhe.2000.0002

35. Lavis JN, Ross SE, Hurley JE. Examining the role of health services research in public policymaking. The Milbank Quarterly 2002; 80(1): 125-154. https://doi.org/10.1111/1468-0009. 00005 
36. Lavis J, Davies H, Oxman A, Denis JL, Golden-Biddle K, Ferlie E. Towards systematic reviews that inform health care management and policy-making. Journal of Health Services Research and Policy 2005; 10(Suppl 1): 35-48. https://doi.org/10.1258/ 1355819054308549

37. Nutley S. Bridging the policy/research divide: reflections and lessons from the UK. In F Mulan (Ed.). Facing the future: engaging stakeholders and citizens in developing public policy. Canberra, ACT: National Institute of Governance Conference, 2003; 1-20.

38. Nutley S, Davies H, Smith P. What works? Evidence-based policy and practice in public services. Bristol, UK: The Policy Press, 2000.

39. Nutley S, Walter I, Davies H. Using evidence: how research can inform public services. Bristol, UK: The Policy Press, 2007.

40. Davies H, Nutley S, Smith P. Introducing evidence-based policy and practice in public services. In: S Nutley, H Davies, P Smith (Eds). What works? Evidence-based policy and practice in public services. Bristol, UK: The Policy Press, 2000; 1-11. https://doi.org/ 10.1332/policypress/9781861341914.003.0001

41. National Oral Health Plan. Healthy mouths, healthy lives - 2004 2013. (Internet) 2004. Available: http://oralhealthplan.com.au (Accessed 6 February 2016).

42. Ministry of Health. Good oral health for all, for life: the strategic vision for oral health in New Zealand. Wellington, New Zealand: Ministry of Health, 2006.

43. Centers for Disease Control and Prevention. Oral health program strategic plan 2011-2014. Atlanta, GA: CDC, 2011.

44. Canadian Association of Public Health Dentistry. A Canadian oral health strategy -2005-2010. (Internet) 2004. Available: http://www.caphd.ca/canadian-oral-health-reports (Accessed 6 February 2016).

45. Department of Health. Choosing better oral health: an oral health plan for England. London: Department of Health, 2005.
46. National Health Service Scotland. An action plan for improving oral health and modernising NHS dental services in Scotland. (Internet) 2005. Available: http://www.gov.scot/Resource/Doc/37428/ 0012526.pdf (Accessed 6 February 2016).

47. Department of Health, Social Services, and Public Safety. Oral health strategy for Northern Ireland. )Internet) 2007. Available at: http://www.dhsspsni.gov.uk/2007_06_25_ohs_full_7.0.pdf (Accessed 6 February 2016).

48. Welsh Government. Together for health: a National Oral Health Plan for Wales (2013-18). (Internet) 2013. Available: http://gov. wales/topics/health/cmo/professionals/dental/oral-plan/?lang =en (Accessed 6 February 2016).

49. Smith AE, Humphreys MS. Evaluation of unsupervised semantic mapping of natural language with Leximancer concept mapping. Behavior Research Methods 2006; 38(2): 262-279. https://doi.org/10.3758/BF03192778

50. Fairclough N. Critical discourse analysis. London, UK: Longman, 1995.

51. Bell E, Seidel B. The evidence-policy divide: a critical computational linguistics approach to the language of 18 health agency CEOs from 9 countries. BMC Public Health 2012; 12(932): $1-15$.

52. Koh HK, Rajkumar R, McDonough JE. Reframing prevention in the era of health reform. Journal of the American Medical Association 2016; 316(10): 1039-1040. https://doi.org/10.1001/jama.2016. 10405

53. Sgan-Cohen HD, Evans RW, Whelton $\mathrm{H}$, et al. International Association of Dental Research global oral health inequalities research agenda (IADR-GOHIRA ${ }^{\circledR}$ ): a call to action. Journal of Dental Research 2013; 92(3): 209-211. https://doi.org/10.1177/ 0022034512475214

54. Kornman KS, Loesche WJ. Subgingival microflora during pregancy. Journal of Periodontal Research 1980; 15: 111-122. https://doi.org/10.1111/j.1600-0765.1980.tb00265.x 
55. Moore WEC, Moore LVH. The bacteria of periodontal diseases. Periodontology 2000 1994; 5(1): 66-77.

56. McGregor JA, French JI, Parker R, et al. Prevention of premature birth by screening and treatment for common genital tract infections: results of a prospective controlled evaluation. American Journal of Obstetrics and Gynaecology 1995; 173(1): 157-167. https://doi.org/10.1016/0002-9378(95)90184-1

57. Novy MJ, McGregor JA, Iams J. New perspectives on the prevention of extreme prematurity. Clinical Obstetrics and Gynaecology 1995; 38(4): 790-808. https://doi.org/10.1097/ 00003081-199538040-00013

58. López NJ, Da Silva I, Ipinza J, Gutiérrez J. Periodontal therapy reduces the rate of preterm low birth weight in women with pregnancy-associated gingivitis. Journal of Periodontology 2005; 76(11-s): 2144-2153. https://doi.org/10.1902/jop.2005.76.11S. 2144

59. Mealey BL, Rose MF. Diabetes mellitus and inflammatory periodontal diseases Current Opinion in Endocrinology, Diabetes \& Obesity 2008; 15(2): 135-141. https://doi.org/10.1097/ MED.0b013e3282f824b7

60. Taylor GW, Borgnakke WS. Periodontal disease: associations with diabetes, glycemic control and complications. Oral Diseases 2008; 14(3): 191-203. https://doi.org/10.1111/j.1601-0825. 2008.01442.x

61. Teeuw WJ, Gerdes VEA, Loos BG. Effect of periodontal treatment on glycemic control of diabetic patients: a systematic review and meta-analysis. Diabetes Care 2010; 33(2): 421-427. https://doi.org/10.2337/dc09-1378
62. Williams RC, Barnett AH, Claffey $\mathrm{N}$, et al. The potential impact of periodontal disease on general health: a consensus view. Current Medical Research and Opinion 2008; 24(6): 1635-1643. https://doi.org/10.1185/03007990802131215

63. Scannapieco FA, Ho AW. Potential associations between chronic respiratory disease and periodontal disease: analysis of National Health and Nutrition Examination Survey III. Journal of Periodontology 2001; 72(1): 50-56. https://doi.org/10.1902/ jop.2001.72.1.50

64. Yoneyama T, Yoshida M, Ohrui $\mathrm{T}$, et al. Oral care reduces pneumonia in older patients in nursing homes. Journal of the American Geriatric Society 2002; 50(3): 430-433. https://doi.org/ $10.1046 / j .1532-5415.2002 .50106 . x$

65. Watando A, Ebihara S, Ebihara T, et al. Daily oral care and cough reflex sensitivity in elderly nursing home patients. Chest 2004; 126(4): 1066-1070. https://doi.org/10.1378/chest. 126.4.1066

66. Pierce JJ, Siddiki S, Jones MD, Schumacher K, Pattison A, Peterson H. Social construction and policy design: a review of past applications. The Policy Studies Journal 2014; 42(1): 1-29. https:// doi. org/10.1111/psj. 12040

67. Coffman J. Evaluation based on theories of the policy process. The Evaluation Exchange, Harvard Graduate School of Education 2007; XIII(1\&2, Spring): 1-3.

68. COAG Health Council. Healthy mouths, healthy lives: Australia's National Oral Health Plan 2015-2024. (Internet) 2015. Available: http://www.coaghealthcouncil.gov.au/Portals/0/Australia\%27s \%20National\%20Oral\%20Health\%20Plan\%202015-2024_ uploaded\%20170216.pdf (Accessed 6 February 2016). 